\title{
Analysis of Spatial and Temporal Climate Characteristics in North Eastern Ethiopia: Case Study of North Wollo Zone
}

\author{
Wagaye Bahiru ${ }^{1}$, Eshetu Zewdu ${ }^{2}$ \\ ${ }^{1}$ National Meteorology Agency of Ethiopia, Kombolcha, Ethiopia \\ ${ }^{2}$ Ethiopian Institutes of Agricultural Research, Addis Ababa, Ethiopia
}

Email address:

wagluckyman@gmail.com (W. Bahiru)

\section{To cite this article:}

Wagaye Bahiru, Eshetu Zewdu. Analysis of Spatial and Temporal Climate Characteristics in North Eastern Ethiopia: Case Study of North Wollo Zone. International Journal of Energy and Environmental Science. Vol. 6, No. 3, 2021, pp. 57-67. doi: 10.11648/j.ijees.20210603.12

Received: July 20, 2021; Accepted: July 30, 2021; Published: August 5, 2021

\begin{abstract}
In Ethiopia, agriculture is the most important sector; the corner stone of the economy; which is a source of livelihood for more than $85 \%$ of Ethiopians; and contributes nearly $50 \%$ of the Growth Domestic Product (GDP) of the country. However, the production performance of the sector is largely depending on the good will of seasonal climate characteristics due to its long-lasting marriage of rain-fed based farming system. Therefore, this study was aimed to investigate the climate characteristics of a region, in north eastern Ethiopia, using seventeen meteorological stations having 31 years of observed rainfall and temperature time series data. Rainfall variability of annual and seasonal climate characteristics were subjected for rainfall anomaly index and coefficient of variation statistics and Mann-Kendall trend test approach were applied to investigate trends of rainfall and temperature in the region over the last 31-years. The result shows that rainfall and temperature were varied across location and time. In this region, mean annual rainfall ranges from $531 \mathrm{~mm}$; over some pocket areas of western, central and north eastern parts; to $1005 \mathrm{~mm}$ in south eastern region of north Wollo. In terms of rainfall distribution, the area receives rainfall two times a year; from June to September (kiremt) and from Mid-February to Mid-May (Belg) period. In this regard, rainfall during belg is highly erratic and unstable relative to the main growing season. The location wide analysis concluded that variation in season onset; cessation and growing season length were observed across from location to location. According to the study, 4-July (DOY=166) and 4-Octoner (DOY=278), in respective order, were estimated as mean dates that the season starts and ends. Further, the analysis revealed, in general, the season onset ranges from 15-June (at Lalibela) to 16July (at Tekulishi); and end of growing season varies from 21-September (Zobil) to 15-October (Sirinka). In general, investigating annual and seasonal climate characteristics; particularly the characteristics of onset, cessation and length of growing season: helps to undertake manageable farming practices that would be suited with local climate potentials. Indeed, climate information has a huge impact on management of seasonal farming activities that would be undertaken during preseason, in season, and post season farming activities.
\end{abstract}

Keywords: Climate, Variability, Trend, Mann-Kendall

\section{Introduction}

Agriculture in Ethiopia is the most important economic sector which is highly exposed to climate induced risks. The sector is a source of livelihood for more than $85 \%$ of Ethiopians; which contributes nearly $50 \%$ of the Growth Domestic Product (GDP); and covers around 90\% of the national export system [32, 10]. However, Agriculture in Ethiopia is highly sensitive and most vulnerable to the increasing trends of climate variability and change. Drought, flood and heat stresses are the most common climate induced risks having a devastating impact on crop and livestock production $[33,17]$.

The production performance of agriculture, in Ethiopia, is high correlated with seasonal climate patterns; mainly rainfall; that bad (low and erratic) seasonal rainfall contributes for poor production performance and good performance is related with good seasonal pattern of rainfall. So unfavorable weather and climate conditions has a direct negative impact on the improvement of food security program of the country.

Climate variability plays a great role in agricultural 
production having a direct impact from the start of land preparation to the final harvest $[3,15]$. Africa in general and the sub-Saharan region in particular is commonly identified as a region that highly affected by climate variability and change due to their low adaptive capacity and high exposure of the climate related risks. Ethiopia is very redundantly exposed for drought risks in the recent half century [4] which directly associated with complete and partial failure of crop during the growing season of the year.

Reports strongly agreed that observed variation in climate and weather conditions, such as recurrent droughts, heat waves, shift in onset and cessation, short duration of growing season, erratic and uneven rainfall distribution and long dry spell conditions during the growing season-significantly affecting the efforts of sustaining food production in Ethiopia with more severity in rural communities subsists in dry areas $[32,9,30,15]$. According to the report of food and agriculture organization, increasing population, land degradation, and frequent droughts results frequent food crises in Ethiopia [12]. In Ethiopia, climate plays a significant role in explaining variation in crop net income and food security levels. Average precipitation and temperature during the rainy season is positively and significantly associated with food security and crop net income. Results also show a large geographical variation in crop income and food security $[12,34]$.

Therefore, understanding the seasonal patterns of climatic conditions are the most crucial point to manage and identify the possible climatic risks of a given location in respective the production season. Having the information, helps to develop appropriate measures; like to select adapted crops/varieties, to choose best sowing time and land management practices; in respective of the location and the seasonal climate situation of the area [11].

It is therefore, the strategic objective of this research was

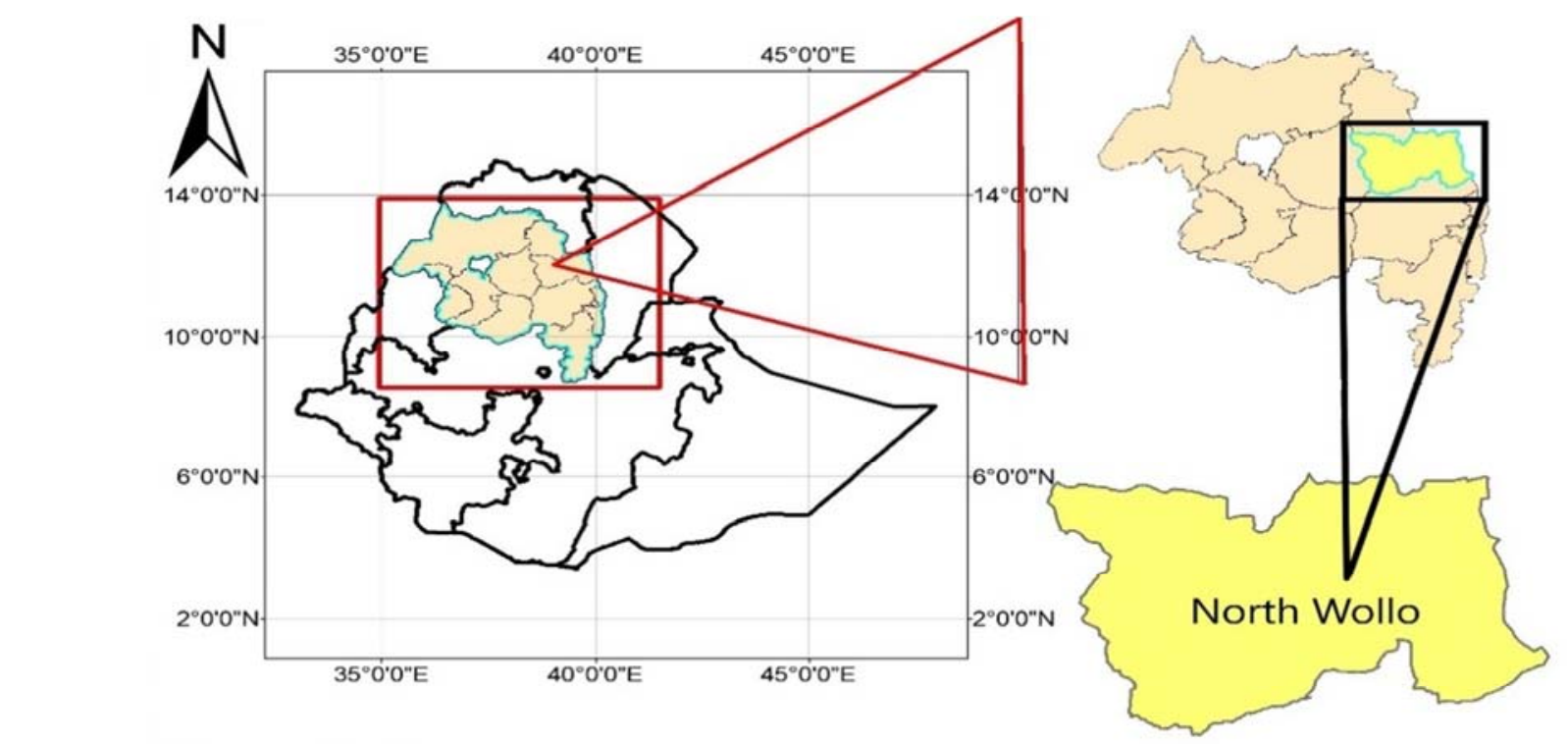

$1: 6,576,642$ to study the historical climate characteristics of the region for optimal utilization of climate resources for agriculture research and development systems.

\section{Materials and Methods}

\subsection{Description of the Study Area}

The study was conducted in North Wollo Zone, North Eastern Ethiopia located between $11^{\circ} \mathrm{N}-13^{\circ} \mathrm{N}$ and $38^{\circ} \mathrm{E}$ to $40^{\circ} \mathrm{E}$ (see figure 1). It covers an area of $12,172.5$ square kilometers, of which $47.3 \%$ is degraded, $24 \%$ is arable, $17.4 \%$ shrub-land, $4.6 \%$ pasture, $0.37 \%$ forest, and the remaining $6.3 \%$ for all other uses (Yassin, 2002). Most of the areas are unsuitable for agriculture as several part of the zone is mountainous and steep slopes, which severely limits the cultivated area. According to the national census conducted by the Central Statistical Agency of Ethiopia this Zone has a total population of 1,500,303 of whom752, 895 are men and 747,408 women (CSA, 2007). The altitude of the zone varies from 600 to 4284 meter above sea level (m.a.s.l). The study region covers four agro-ecological zones, namely, lowland (500-1500masl), Mid-altitude (1500-2300 masl), highland (2300-3200 masl) and Wurch (>3200masl). The region is characterized by two rainy seasons, the long rainy season from June to September (locally called kiremt) and the short rainy season from February to May (locally known as belg).

The annual rainfall of the region ranges from 525.8 to $919.6 \mathrm{~mm}$ on average. The seasonal rainfall ranges from 256.5 to $701.2 \mathrm{~mm}$ and $48.5-255.6 \mathrm{~mm}$ during the main (June to September) and short (February to May) growing season respectively. On the other hand, the mean annual maximum, minimum and average temperatures are $24.7^{\circ} \mathrm{C}, 11.4^{\circ} \mathrm{C}$ and $18.4^{\circ} \mathrm{C}$ respectively over the study area.

Figure 1. Map of the study location. 
Table 1. Location of meteorological stations used in this study.

\begin{tabular}{lllll}
\hline $\begin{array}{l}\text { Station } \\
\text { name }\end{array}$ & Latitude & Longitude & Altitude & $\begin{array}{l}\text { Year of } \\
\text { observation }\end{array}$ \\
\hline Ayinabugna & 12.17 & 38.84 & 2661 & $1987-2017$ \\
Lalibela & 12.04 & 39.04 & 2487 & $1987-2017$ \\
Muja & 12.01 & 39.29 & 2790 & $1987-2017$ \\
Kulmesk & 11.93 & 39.20 & 2362 & $1987-2017$ \\
Kobo & 12.13 & 39.63 & 1468 & $1987-2017$ \\
Debrezebit & 11.81 & 38.58 & 2917 & $1987-2017$ \\
Kone & 11.61 & 38.93 & 2890 & $1987-2017$ \\
Gashena & 11.67 & 38.92 & 2969 & $1987-2017$ \\
Shoga & 11.48 & 38.99 & 2411 & $1987-2017$ \\
Hara & 11.84 & 39.74 & 1509 & $1987-2017$ \\
Woldia & 11.83 & 39.59 & 1894 & $1987-2017$ \\
Mersa & 11.66 & 39.67 & 1578 & $1987-2017$ \\
Sirinka & 11.75 & 39.61 & 1861 & $1987-2017$ \\
Tekulishi & 12.15 & 39.49 & 2181 & $1987-2017$ \\
Delib & 11.96 & 39.42 & 3276 & $1987-2017$ \\
Zobil & 12.17 & 39.75 & 1893 & $1987-2017$ \\
Debeko & 11.82 & 38.93 & 2106 & $1987-2017$ \\
\hline
\end{tabular}

\subsection{Data Sources and Method of Analysis}

Historical climate data used for this study were obtained from ground-based climate data observation networks of National Meteorological Agency of Ethiopia. Thirty-one year (1987-2017) of historical climate time series data were also taken in to account for analysis.

\subsection{Data Quality Check}

Validity check (quality control) was undertaken for the historical time series climate data prior to undertaking the analysis. In this study, errors due to data digitization and reporting and data internal inconsistency, which minimum temperature higher than maximum temperature and rainfall values less than zero $(0 \mathrm{~mm})$ [24] were evaluated and managed. On the other hand, outliers in a time series data were detected carefully to check that whether the values are really outliers or naturally extreme values [1]. A standard outlier threshold, which is defined using inter-quartile range (IQR), was used to manage the outliers (Gonzalez-Rouco et al, 2001). The threshold values were estimated using the below formula, i.e,

$$
\text { Threshold }=(\mathrm{Q} 1-3 \mathrm{IQR}, \mathrm{Q} 3+3 \mathrm{IQR})
$$

Where, Q1 is first quartile, Q3 is third quartile and IQR is an inter-quartile range (which is the difference of Q3 and Q1). The inter-quartile range method is known as a technique which is resistance to outliers but still keep the information of extremes. The detected outlier values were then removed and substituted by outlier threshold (SUPARI, 2012).

\subsection{Method of Data Analysis}

Coefficient of variation (CV), Standardized Rainfall Anomaly (SRA) and Precipitation Concentration Index (PCI) were computed to see annual and seasonal rainfall variability over the observed periods.

$$
C V(\%)=\frac{\delta}{\bar{X}} * 100
$$

Where, $\mathrm{CV}$ is coefficient of variation in percent, $\bar{X}$ and $\delta$ are mean and standard deviation values respectively.

The degree of variability in rainfall is classified as less $(\mathrm{CV}<20 \%)$ moderate $(\mathrm{CV}=20 \%$ to $30 \%)$ and highly variable (CV $>30 \%$ ) according to the estimated $\mathrm{CV}$ values [5].

$$
S R A=\frac{P t-P m}{\sigma}
$$

The drought severity classes are extreme drought (SRA $<$ $1.65)$, Severe drought $(-1.28>\mathrm{SRA}>-1.65)$, moderate drought $(-0.84>$ SRA $>-1.28)$, and no drought (SRA $>-0.84)$.

$$
P C I=\frac{\left(\sum_{p i} 2\right)}{\left(\sum p i\right) 2} * 100
$$

When a PCI value is less than 10, indicated a uniformity of monthly rainfall distribution in a year, a PCI value from 1115 indicates a moderate precipitation concentration and PCI from 16- 20 indicates irregular distribution a monthly in a year. A PCI value $>20$ shows a strong irregularity in rainfall distribution.

The areal average of rainfall and temperature for the study location is calculated using the below formula [18].

$$
R j=\frac{\sum_{\mathrm{k}=1}^{\mathrm{j}} \mathrm{Xij}}{\mathrm{Ij}}
$$

Where $R_{j}$ is areal integrated rainfall/temperature for year $j$; $\mathrm{Xij}$ is rainfall/temperature at station $\mathrm{i}$ for year $\mathrm{j}$ and $\mathrm{n}_{\mathrm{j}}$ is the number of stations available for year $\mathrm{j}$. Variability and trend in areal rainfall and temperature is also examined using the same methods. The spatial variability of rainfall and temperature for seasonal and annual time scale across stations has been analyzed and mapped using Inverse Distance Weighting (IDW) technique using QGIS software $[28,30]$.

\subsection{Trend Analysis}

To detect the trend and magnitude of rainfall and temperature patterns in a time series, Mann-Kendall's trend test and Sen's slope estimation method were employed. According to Pohlert [23], Mann-Kendall's test is a common method employed to detect monotonic trends in series of environmental, climate and/or hydrological data. MannKendall's method is less sensitive to outliers in a time series without considering whether the trend is linear or nonlinear $[22,35]$.

$$
S=\sum_{i=1}^{N-1}\left(\sum_{j=i+1}^{N} \operatorname{sgn}(x j-x i)\right.
$$

Where $x_{j}$ and $x i$ are the sequential precipitation or temperature values in months $\mathrm{j}$ and $\mathrm{i}(\mathrm{j}>\mathrm{i})$ and $N$ is the length of the time series. A positive $\mathrm{S}$ value indicates an increasing trend and a negative value indicates a decreasing trend in a time series. Variance of $\mathrm{S}$, for the situation where there may be ties (i.e., equal values) in the $\mathrm{x}$ values, is given by 
$\operatorname{Var}(s)=\frac{1}{18}\left[N\left(N-1(2 N+5)-\sum_{i=1}^{m} t i(t i-1)(2 t i+5)\right]\right.$

Where, $m$ is the number of tied groups in the data set and ti is the number of data points in the $\mathrm{i}^{\text {th }}$ tied group. For $\mathrm{n}$ larger than 10 , the standard normal ZMK test statistic is computed as follows [22].

$$
Z M K=\left\{\begin{array}{l}
\frac{S-1}{\sqrt{\operatorname{var}(s)}} S>0 \\
0 S=0 \\
\frac{S+1}{\sqrt{\operatorname{var}(S)}} S<0
\end{array}\right.
$$

The presence of a statistically significant trend is evaluated using the ZMK value. In a two-sided test for trend, the null hypothesis Ho should be accepted if $|Z M K|<Z 1-\alpha / 2$ at a given levelof significance. $Z 1-\alpha / 2$ is the critical value of ZMK from the standard normal table. E.g. for $5 \%$ significance level, the value of $Z 1-\alpha / 2$ is 1.96

\subsection{Sen's Slope Estimator Test}

The magnitude of trend is predicted by the Sen's estimator. The slope (Ti) of all data pair computed as [26]. This test is applied in cases where the trend is assumed to be linear, depicting the Quantification of changes per unit time.

$$
T i=\frac{x j-x k}{j-k}
$$

Where and $\mathrm{Xk}$ are considered as data values of time $\mathrm{j}$ and $k(j>k)$ correspondingly. The median of these $N$ values of $\mathrm{Ti}$ is represented as Sen's estimator of slope which is given as

$$
Q=\left\{\begin{array}{c}
\frac{1}{2}\left(T \frac{N}{2}+T \frac{N+2}{2}\right) \text { if Nis even } \\
T \frac{N+1}{2}, \text { if Nis odd }
\end{array}\right.
$$

Positive value of Qi indicates an upward or increasing trend and a negative value indicates downward or decreasing trend in the time series.

To summarize the daily climate data, Instat+v3.7, GenStat and XLSTAT software packages were used. QGIS was also come in to action to interpolate and map seasonal and annual rainfall distribution of the study region using inverse distance weighting interpolation approach.

\section{Result and Discussions}

\subsection{Annual and Seasonal Rainfall Distribution}

Spatial distribution of mean annual and seasonal rainfall of the study region is presented in the below figure (Figure 4). According to 1987-2017 observed climate data, mean annual rainfall is varied from $531 \mathrm{~mm}$; over some pocket areas of western, central and north eastern parts; to $1005 \mathrm{~mm}$ in south eastern region of the study area.

The mean annual and kiremt (JJAS) rainfall of the region, based on the study period, is 747.6 and $534.9 \mathrm{~mm}$ respectively.
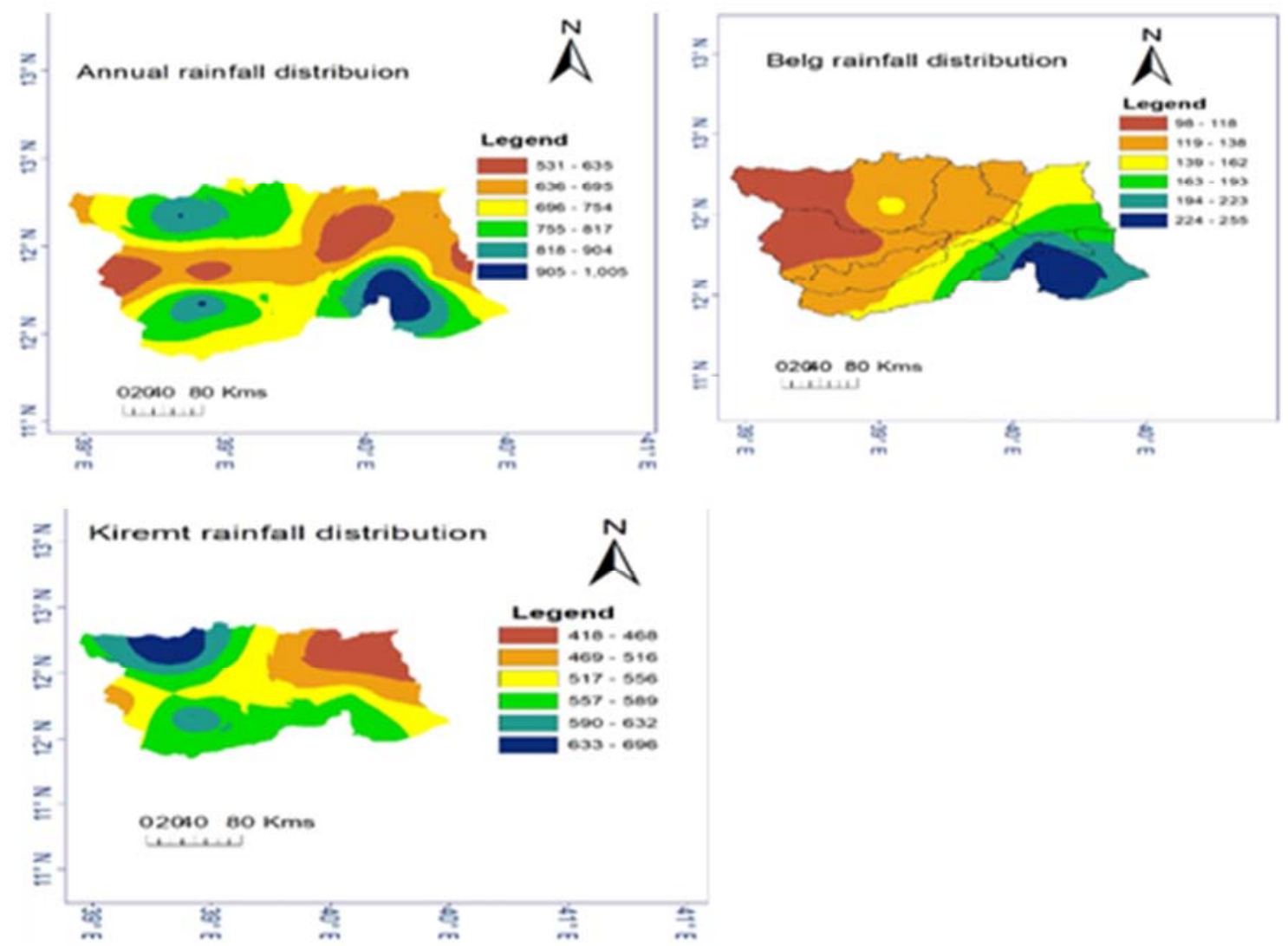

Figure 2. Spatial distribution of annual and seasonal rainfall (mm) of north wollo zone (1987-2017). 
In terms of rainfall distribution, the area receives rainfall two times a year; from June to September (kiremt) and from February to May (Belg) period. June to September (Kiremt) is the main rainy season which most agricultural/farming/ operations undertaken, whereas, belg (February to May) is the short rainy period that land preparation practices for the main growing season and long maturing sorghum and maize planting begins.

The mean areal rainfall during the main (June to September) and small (February to May) growing season
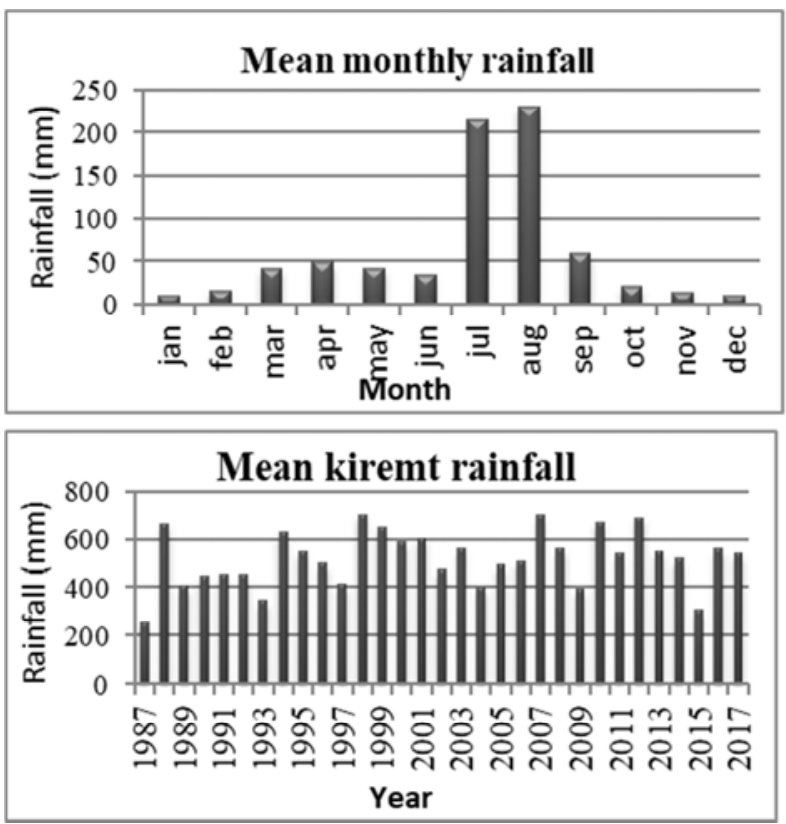

respectively is 534.9- and $151.5-\mathrm{mm}$. June to September (kiremt) is the major contributor (58 to $85 \%$ ) of the annual total rainfall followed by Belg (February to May) season which has a 10 to $30 \%$ contribution of the annual total rainfall. This finding is agreed with previous studies undertaken by Bewket and Conway; Ayalew et al., [8, 7]. Those studies strongly agreed and concluded that, Kiremt is the major contributor of the annual total rainfall followed by February to May (Belg) season.
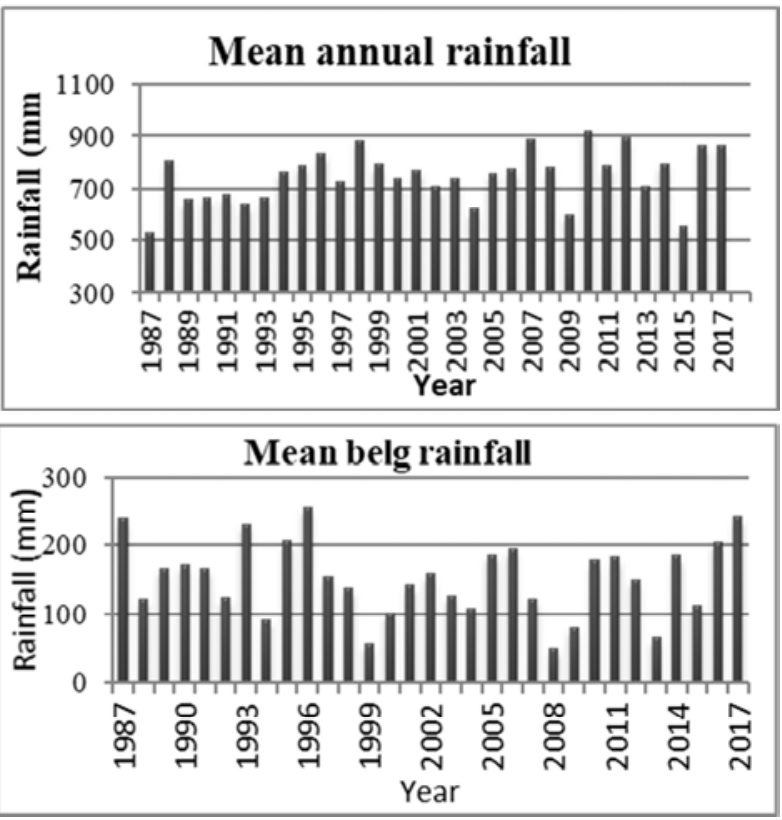

Figure 3. Mean monthly, annual and seasonal rainfall distribution in North Wollo Zone (1987-2017).

\subsection{Trend and Variability}

Understanding trend and variation of annual and seasonal rainfall is very important for strategic planning of agricultural practices like what and where to practice such operations [28]. The analysis result of historical rainfall time series data indicated that magnitude of rainfall variability differs across location and season. The coefficient of variation statistics indicated that annual rainfall variability of the region ranges from $17.5 \%$ (Debeko station) to $\mathrm{CV}=46.5 \%$ (Shoga station). Whereas, rainfall variability during the main growing season (Kiremt) varies from $\mathrm{CV}=20 \%$ to $51 \%$; and $\mathrm{CV}=44.2 \%$ to $96 \%$ during the short growing season (Belg). The result also indicated that the amount of rainfall received during the short rainy season (Belg) is highly unstable relative to the main growing season (Kiremt). The seasonal rainfall variability was higher than the annual variability over the study area. This agrees with the findings of previous studies conducted in Ethiopia [25, 6]. Moreover, higher $\mathrm{CV}$ of annual/or seasonal rainfall of the region implying that large year to year or season to season variation of rainfall. In general, large inter-seasonal/ or inter-annual variability of rainfall could also negatively affect farming operations that could be undertaken in both large scale and small-scale systems. The statistics computed based on the historical rainfall data; such as mean, coefficient of variation (CV) and percentage contributions of seasonal rainfall to annual rainfall of the selected stations are presented in Table 2.

Table 2. Mean annual and seasonal rainfall (mm), coefficient of variation (CV\%) and contribution of seasonal rainfall to the annual rainfall (CT\%) for representative meteorological stations.

\begin{tabular}{|c|c|c|c|c|c|c|c|c|c|c|c|}
\hline \multirow{2}{*}{ Stations } & \multicolumn{3}{|c|}{ Kiremt rainfall } & \multicolumn{3}{|c|}{ Belg rainfall } & \multicolumn{3}{|c|}{ Bega rainfall } & \multicolumn{2}{|c|}{ Annual rainfall } \\
\hline & Mean & CV (\%) & CT (\%) & Mean & CV (\%) & CT (\%) & Mean & CV (\%) & CT (\%) & Mean & CV (\%) \\
\hline Ayinabugna & 775.5 & 34.9 & 85 & 94.4 & 50.2 & 10.3 & 42.5 & 98.6 & 4.7 & 912.4 & 28.8 \\
\hline Lalibela & 542.9 & 22.4 & 71.9 & 187.7 & 57.7 & 24.8 & 59.9 & 64.5 & 7.9 & 755.2 & 26.4 \\
\hline Muja & 527.6 & 35.6 & 76.8 & 131.6 & 50.4 & 19.1 & 28.2 & 101.9 & 4.1 & 687.3 & 29.2 \\
\hline Kulmesk & 508.3 & 32.8 & 79.2 & 99.8 & 48.4 & 15.5 & 35.6 & 98.1 & 5.5 & 642.2 & 23.2 \\
\hline Kobo & 402.5 & 34.0 & 61.3 & 178.3 & 95.9 & 27.2 & 75.6 & 72.3 & 11.5 & 656.5 & 33.1 \\
\hline
\end{tabular}




\begin{tabular}{|c|c|c|c|c|c|c|c|c|c|c|c|}
\hline \multirow{2}{*}{ Stations } & \multicolumn{3}{|c|}{ Kiremt rainfall } & \multicolumn{3}{|c|}{ Belg rainfall } & \multicolumn{3}{|c|}{ Bega rainfall } & \multicolumn{2}{|c|}{ Annual rainfall } \\
\hline & Mean & CV (\%) & CT (\%) & Mean & CV (\%) & CT (\%) & Mean & CV (\%) & CT (\%) & Mean & CV (\%) \\
\hline Debrezebit & 420.2 & 36.8 & 79.3 & 84.9 & 45.5 & 16.0 & 24.7 & 82.9 & 4.7 & 529.8 & 31.6 \\
\hline Kone & 583.7 & 19.9 & 70.6 & 144.9 & 59.3 & 17.5 & 37.4 & 66.4 & 4.5 & 827.0 & 29.4 \\
\hline Gashena & 740.3 & 44.5 & 79.6 & 142.2 & 49.5 & 15.3 & 47.5 & 72.0 & 5.1 & 930.2 & 37.2 \\
\hline Shoga & 563.8 & 51.0 & 78.3 & 124.0 & 56.2 & 17.2 & 32.0 & 78.1 & 4.4 & 719.9 & 46.5 \\
\hline Hara & 458.1 & 31.4 & 67.1 & 155.6 & 60.2 & 22.8 & 68.9 & 89.2 & 10.1 & 682.7 & 24.1 \\
\hline Woldiya & 606.3 & 30.6 & 61.2 & 246.7 & 44.2 & 24.9 & 107.9 & 61.1 & 10.9 & 991.4 & 23.8 \\
\hline Mersa & 594.6 & 29.5 & 59.6 & 280.0 & 51.2 & 28.1 & 122.4 & 64.6 & 12.3 & 996.9 & 22.0 \\
\hline Sirinka & 584.1 & 28.9 & 58.1 & 285.5 & 46.9 & 28.4 & 135.3 & 67.5 & 13.5 & 1005 & 20.8 \\
\hline Tekulishi & 418.8 & 32.1 & 74.0 & 106.5 & 54.1 & 18.8 & 40.5 & 87.7 & 7.2 & 565.7 & 22.6 \\
\hline Delib & 459.0 & 33.4 & 79.6 & 86.8 & 63.2 & 15.1 & 21.7 & 107.1 & 3.8 & 576.8 & 20.7 \\
\hline Zobil & 418.5 & 44.2 & 66.1 & 143.5 & 53.6 & 22.7 & 78.8 & 84.2 & 12.3 & 632.9 & 32.8 \\
\hline Debeko & 488.9 & 23.0 & 81.9 & 82.9 & 45.4 & 13.9 & 27.8 & 66.9 & 4.7 & 596.7 & 17.5 \\
\hline Areal mean & 534.9 & 29.3 & 71.9 & 151.5 & 36.2 & 20.4 & 56.2 & 54.8 & 7.6 & 747.6 & 23.4 \\
\hline
\end{tabular}

In addition to the CV statistics, standardized rainfall anomaly index (SRA) were also used to investigate inter-annual variation of rainfall of the study area. The result revealed that, irregular pattern of annual and seasonal rainfall deviation was observed in the last 31-years. Furthermore, the region is characterized by periodic fluctuation of wet and dry years in both annual and seasonal basis. An annual and seasonal rainfall anomaly of the region is presented in Figure 4. The standard rainfall anomaly result indicated that the tendency of annual rainfall towards negative (dry) and positive (wet) deviation is $45.2 \%$ and $54.8 \%$ respectively. On the other hand, the region experienced 15 dry and 16 wet years during the main growing season (June to September) since 1987 to 2017 . Additionally, the dry and wet severity of annual and seasonal rainfall relative to the historical mean rainfall is varied in magnitude. According to Agnew and Chappel [2] drought assessment method, North wollo experienced five driest years; which two extremes (1987 and 2015), two severe (2004 and 2009) and one moderate (1992) dry years; from 1987 to 2017. The region also (North wollo) experienced two severe wet years (in 2007 and 2012), one extremely severe year (in 2010), and two moderate wet years (in 2016 and 2017) over the study period.

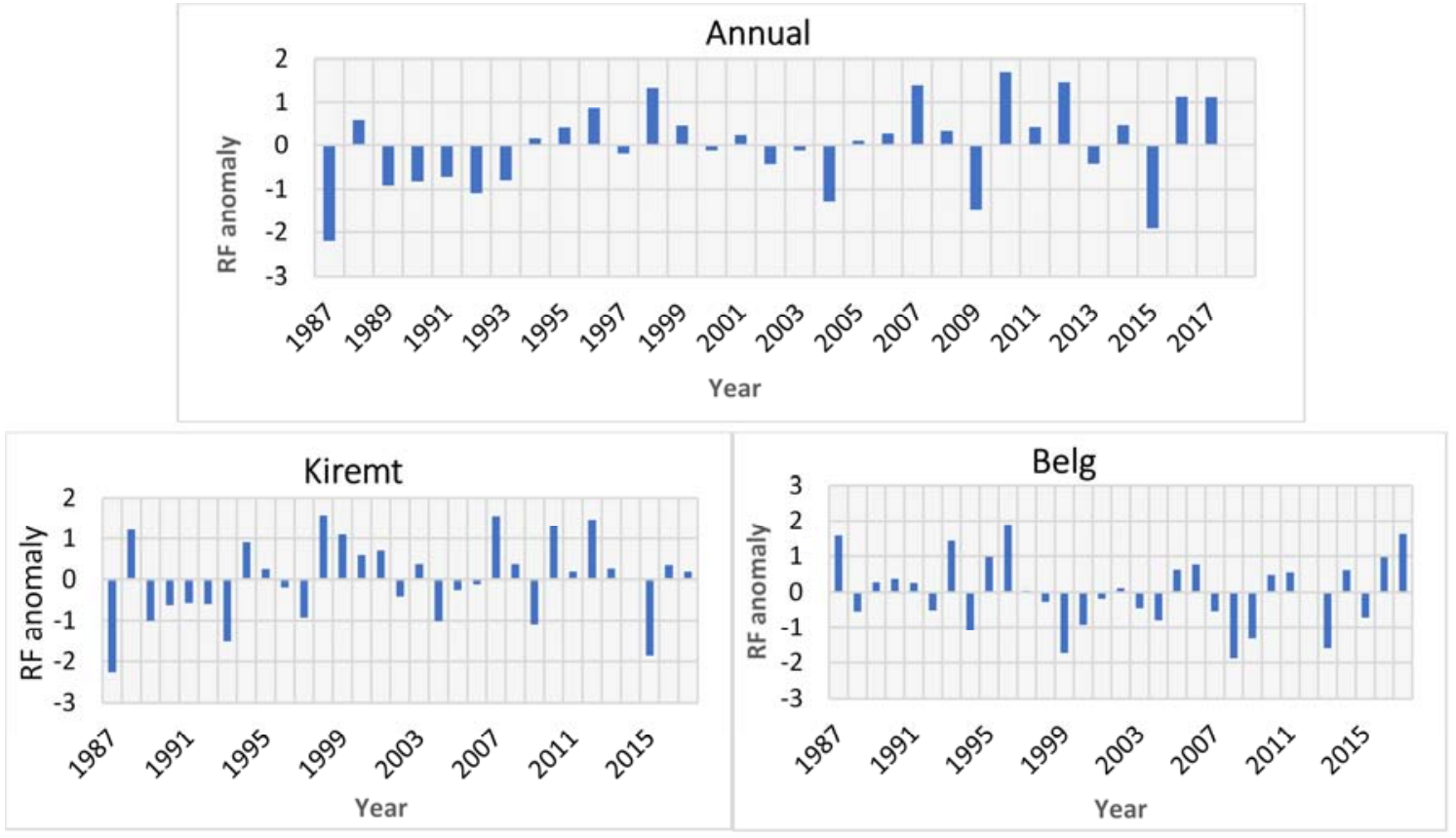

Figure 4. Deviation of annual and seasonal areal rainfall from the long-term averages (1987-2017).

Mean annual and seasonal (Kiremt and belg) time series rainfall data from 1987 to 2017 were organized to detect trend and magnitude of rainfall over the recorded periods. As presented in Table 3, spatial and temporal rainfall variations were exhibited in North Wollo from 1987 to 2017. According to the result, increasing of annual and kiremt (June to September) rainfall; and a decreasing trend of belg (February to May) rainfall were observed over the last 31 years in the region. With this, annual and kiremt (June to September) rainfall increased at the rate of 34.4 and $44.4 \mathrm{~mm} /$ decade $(10$ year), while belg rainfall declined by $8.7 \mathrm{~mm}$ per decade. Yet, the change in annual and seasonal rainfall observed over the region was not statistically significant. In some areas of the region; such as Gashena (179 $\mathrm{mm} /$ decade), Woldiya (151 $\mathrm{mm} /$ decade) and Hara (87 mm/decade); annual and kiremt rain were significantly increased (Table 3 ). 
Table 3. Mann-Kendall trends test result of annual and seasonal (Belg and Kiremt) rainfall (1987-2017).

\begin{tabular}{|c|c|c|c|c|c|c|c|c|c|}
\hline \multirow{2}{*}{ Stations } & \multicolumn{3}{|c|}{ Annual Rainfall } & \multicolumn{3}{|c|}{ Kiremt Rainfall } & \multicolumn{3}{|c|}{ Belg Rainfall } \\
\hline & ZMK & $\mathbf{Q}$ & P-value & ZMK & $\mathbf{Q}$ & P-Value & ZMK & $\mathbf{Q}$ & P-value \\
\hline Ayinabugna & 0.26 & 12.4 & 0.051 & 0.25 & 12.1 & 0.040 & 0.024 & 0.235 & 0.866 \\
\hline Lalibela & -0.07 & -1.60 & 0.57 & 0.25 & 4.23 & 0.040 & -0.234 & -3.91 & 0.066 \\
\hline Muja & 0.16 & 4.30 & 0.21 & 0.2 & 4.52 & 0.110 & 0.059 & 0.20 & 0.89 \\
\hline Kumesk & -0.13 & -4.10 & 0.29 & -0.12 & -4.19 & 0.344 & -0.120 & -1.00 & 0.370 \\
\hline Kobo & -0.03 & -1.10 & 0.81 & 0.14 & 3.34 & 0.279 & -0.220 & -2.65 & 0.089 \\
\hline Debrezebit & -0.37 & -1.10 & 0.00 & -0.33 & -9.17 & 0.008 & -0.248 & -1.63 & 0.053 \\
\hline Gashena & 0.36 & 17.9 & 0.00 & 0.39 & 15.5 & 0.002 & 0.039 & 0.59 & 0.773 \\
\hline Shoga & 0.22 & 6.60 & 0.08 & 0.29 & 9.33 & 0.019 & 0.086 & 1.00 & 0.507 \\
\hline Hara & 0.32 & 8.70 & 0.01 & 0.23 & 5.58 & 0.066 & 0.127 & 2.11 & 0.327 \\
\hline Woldia & 0.36 & 15.1 & 0.00 & 0.43 & 12.1 & 0.001 & 0.060 & 0.93 & 0.646 \\
\hline Mersa & -0.05 & -2.42 & 0.69 & 0.14 & 4.60 & 0.279 & -0.169 & -3.21 & 0.187 \\
\hline Sirinka & 0.11 & 4.50 & 0.42 & 0.20 & 5.70 & 0.111 & -0.060 & -2.26 & 0.646 \\
\hline Tekulishi & -0.16 & -3.10 & 0.21 & 0.03 & 1.00 & 0.798 & -0.160 & -1.60 & 0.208 \\
\hline Delib & -0.21 & -3.36 & 0.09 & -0.02 & -0.22 & 0.893 & -0.198 & -1.75 & 0.122 \\
\hline Debeko & 0.02 & 0.34 & 0.85 & 0.16 & 2.77 & 0.211 & -0.171 & -1.14 & 0.185 \\
\hline Areal mean & 0.06 & 3.44 & 0.30 & 0.15 & 4.44 & 0.25 & -0.07 & -0.87 & 0.45 \\
\hline
\end{tabular}

\subsection{Onset, Cessation Date and Length of Growing Period}

Analysis of seasonal climate characteristics; onset, retreat, length of growing season (LGP) and number of rainy days; were investigated for the main growing (June to September) rainy season using historical rainfall data. According to Sonnadara and Mugalavai et al. [27, 18], detail studies of seasonal climate characteristics like onset, retreat, length of growing season and dry spell characteristics are very crucial to manage the climate resources, thus, to manage agricultural/cropping/ practices of a given region. Table 4 shows statistics of estimated mean onset, cessation, LGP, rainy days and coefficient of variation summarized per station. The results showed that, during the long rainy season, 4-July $(\mathrm{DOY}=166)$ and 4-Octoner $(\mathrm{DOY}=278)$ are estimated mean onset and retreat dates respectively. The results also revealed that onset and retreat dates were varied across stations which considered under the study region. In the study region, rainfall starts from 15-June (at Lalibela) to 16July (at Tekulishi); and terminate from 21-Sept (Zobil) to 15October (Sirinka). In general, onset of rains was found to be predominantly in the month of June/July, and the season retreats in September/October. This agrees with the study by Hadigu et al. [13]. The length of growing season and number of rainy days also varied from 73 to 110 -days and 37 to 61 days, respectively, across the region. The CV statistic results indicated that, most of the stations were exhibited less interannual onset variation from 1987 to 2017 study period. On the other hand, moderate to higher variability of season end dates and growing season length were observed across the region. This is significantly increasing the risks of water stress during vegetative and flowering stages, the period which water demand of plants increased, and, therefore, causes quality and quantity loss of production.

Table 4. Summary statistics for onset, cessation, LGP, rainy days and coefficient of variation (1987 to 2017).

\begin{tabular}{|c|c|c|c|c|c|c|c|}
\hline \multirow{2}{*}{ Stations } & \multicolumn{2}{|l|}{ Onset } & \multirow{2}{*}{$\begin{array}{l}\text { Cessation } \\
\text { Mean }\end{array}$} & \multicolumn{2}{|c|}{ Length of growing period } & \multicolumn{2}{|c|}{ Number of rainy days } \\
\hline & Mean & CV (\%) & & Mean & CV (\%) & Mean & CV (\%) \\
\hline Ayinabugna & 185 (3-Jul) & 6.9 & 281 (7-Oct) & 96 & 23.1 & 58 & 28 \\
\hline Lalibela & 168 (16-Jun & 9.7 & 278 (4-Oct) & 110 & 18.1 & 61 & 27.5 \\
\hline Muja & 190 (8-Jul) & 7.4 & 278 (4-Oct) & 89 & 28.3 & 50 & 28.7 \\
\hline Kulmesk & 186 (4-Jul) & 7.9 & 279 (5-Oct) & 94 & 21.6 & 54 & 22.1 \\
\hline Kobo & 193 (11-Jul) & 9.8 & 286 (12-Oct) & 93 & 34.4 & 39 & 30.4 \\
\hline Debrezebit & 190 (8-Jul) & 7.9 & $276(2-\mathrm{Oct})$ & 85 & 18.2 & 51 & 33.7 \\
\hline Kone & 182 (30-Jun) & 6.7 & 278 (4-Oct) & 96 & 14.9 & 50 & 37.7 \\
\hline Gashena & 183 (1-Jun) & 7.6 & 277 (3-Oct) & 95 & 17 & 53 & 46.6 \\
\hline Shoga & 188 (6-Jul) & 5.8 & 276 (2-Oct) & 88 & 13 & 44 & 34.1 \\
\hline Hara & 189 (7-Jul) & 8.7 & 280 (6-Oct) & 91 & 24.8 & 48 & 31.1 \\
\hline Woldiya & 184 (2-Jul) & 10.4 & 286 (12-Oct) & 102 & 46.2 & 49 & 31.8 \\
\hline Mersa & 182 (30-Jun) & 7.9 & 288 (14-Oct) & 106 & 26.4 & 47 & 28.5 \\
\hline Sirinka & $184(2-\mathrm{Jul})$ & 10.1 & 289 (15-Oct) & 105 & 30.9 & 52 & 25.8 \\
\hline Tekulishi & 197 (15-Jul) & 6.3 & 277 (3-Oct) & 79 & 16.3 & 44 & 30.1 \\
\hline Delib & 194 (12-Jul) & 5.5 & 266 (22-Sept) & 73 & 23.6 & 54 & 26.5 \\
\hline Zobil & 184 (2-Jul) & 27.5 & 265 (21-Sept) & 80 & 60.3 & 37 & 40.9 \\
\hline Debeko & 188 (6-Jul) & 5.7 & 266 (22-Sept) & 78 & 18.2 & 48 & 30.5 \\
\hline Areal mean & 166 (4-July) & 8.9 & 278 (4-Oct) & 91.8 & 25.6 & 49.4 & 31.4 \\
\hline
\end{tabular}


Trend and magnitude of onset, cessation and length of growing season of the main season (June to September), which are detected using Mann-Kendall trend test and Sen's slope estimator approach, are displayed in Table 5. During detecting the trend using 1987 to 2017 daily rainfall time series data, $5 \%$ of error were tolerated to reject the null hypothesis of the no trend acceptance during the period. The results indicated that, over the study period, most of the study areas exhibited early onset;( negative or downward trend indicates early onset and positive or upward trend indicates late onset). Cessation and length of growing season shows insignificant increasing trends at $95 \%$ confidence interval.

Table 5. Trend and magnitude of Onset, Cessation and Length of growing season of the main season.

\begin{tabular}{|c|c|c|c|c|c|c|c|c|c|}
\hline \multirow{2}{*}{ Stations } & \multicolumn{3}{|c|}{ Onset date } & \multicolumn{3}{|c|}{ Cessation date } & \multicolumn{3}{|c|}{ Length of growing period } \\
\hline & ZMK & $\mathbf{Q}$ & P-value & ZMK & $\mathbf{Q}$ & P-value & ZMK & $\mathbf{Q}$ & P-value \\
\hline Ayinabugna & -0.06 & -0.10 & 0.63 & 0.07 & 0.00 & 0.62 & 0.05 & 0.10 & 0.72 \\
\hline Lalibela & 0.34 & 0.50 & 0.01 & 0.21 & 0.00 & 0.16 & -0.22 & -0.40 & 0.10 \\
\hline Muja & -0.21 & -0.50 & 0.10 & 0.06 & 0.00 & 0.70 & 0.24 & 0.54 & 0.07 \\
\hline Kumesk & -0.05 & -0.14 & 0.72 & -0.29 & 0.00 & 0.05 & -0.02 & -0.06 & 0.87 \\
\hline Kobo & 0.00 & 0.00 & 1 & 0.18 & 0.00 & 0.19 & 0.12 & 0.45 & 0.35 \\
\hline Debrezebit & 0.00 & 0.00 & 1 & 0.07 & 0.00 & 0.64 & 0.02 & 0.04 & 0.88 \\
\hline Gashena & -0.40 & -0.80 & 0.00 & 0.28 & 0.00 & 0.04 & 0.45 & 1.04 & 0.00 \\
\hline Shoga & -0.13 & -0.21 & 0.30 & 0.22 & 0.00 & 0.14 & 0.14 & 0.23 & 0.28 \\
\hline Hara & -0.27 & -0.61 & 0.04 & 0.12 & 0.20 & 0.39 & 0.29 & 0.78 & 0.02 \\
\hline Woldia & 0.02 & 0.10 & 0.91 & -0.03 & -0.31 & 0.81 & 0.22 & 1.54 & 0.09 \\
\hline Mersa & -0.08 & -0.13 & 0.52 & 0.23 & 0.22 & 0.08 & 0.17 & 0.61 & 0.20 \\
\hline Sirinka & -0.23 & -0.58 & 0.08 & 0.19 & 0.25 & 0.16 & 0.24 & 1 & 0.06 \\
\hline Tekulishi & -0.08 & -0.18 & 0.55 & -0.17 & -0.19 & 0.26 & 0.11 & 0.21 & 0.39 \\
\hline Delib & 0.04 & 0.06 & 0.80 & 0.16 & 0.29 & 0.23 & 0.18 & 0.57 & 0.17 \\
\hline Debeko & 0.02 & 0.01 & 0.89 & 0.21 & 0.20 & 0.11 & 0.16 & 0.38 & 0.22 \\
\hline Areal mean & -0.08 & -0.19 & 0.49 & 0.11 & 0.06 & 0.30 & 0.16 & 0.52 & 0.26 \\
\hline
\end{tabular}

\subsection{Temporal and Spatial Characteristics of Temperature}

Based on 1987 to 2017 observed data, the mean annual maximum and minimum temperature is varied between $19.9^{\circ} \mathrm{C}$ (at Shoga) to $29.4^{\circ} \mathrm{C}$ (at Kobo) and $6.7^{\circ} \mathrm{C}$ (at Mersa) to $14.9^{\circ} \mathrm{C}$ (at Kobo) stations respectively. Similarly, the mean annual air temperature is varied from $13.9^{\circ} \mathrm{C}$ (at Kone) to $22.2^{\circ} \mathrm{C}$ (at Kobo). In this regard, south western and north eastern region of the study areas were exhibited the lower and higher mean annual minimum temperature respectively. On the other hand, the highest and lowest annual maximum temperature records, over the last 31-years, were observed in north eastern and south western parts. Overall, temperature is progressively increased north ward; in which the north eastern region was experienced the maximum warming over the considered time span. The trend analysis results for mean annual air temperature, including maximum and minimum temperature, tested using Mann-Kendall approach are depicted in Table 6. The results, using 1987 to 2017 daily observed temperature data, indicated that most locations of the study region exhibited a significant increasing trend of annual maximum and minimum temperature, while some stations showed decreasing trends. Kone, Woldiya, Delib and Zobil were experienced decreasing annual minimum temperature, while, decreasing annual maximum temperature was observed at Gashena, Zobil and Delib areas. Yet, the observed change in maximum and minimum temperature is insignificant in most locations. Significant increasing trends of annual maximum temperature were observed in most areas of the study region. The highest significant change in annual maximum temperature was observed at Ayinabugna, Hara, Tekulishi and Debeko stations, thus, showed a $0.1{ }^{\circ} \mathrm{C}$ incensement annually.

Table 6. Descriptive statistics of annual, maximum, minimum and average temperature in the study area for the period 1987-2017 well-come.

\begin{tabular}{|c|c|c|c|c|c|c|c|c|c|c|c|c|}
\hline \multirow{2}{*}{ Stations } & \multicolumn{4}{|c|}{ Minimum temperature } & \multicolumn{4}{|c|}{ Maximum temperature } & \multicolumn{4}{|c|}{ Average temperature } \\
\hline & Mean & ZMK & $\mathbf{Q}$ & P-value & Mean & ZMK & $\mathbf{Q}$ & P-value & Mean & ZMK & $\mathbf{Q}$ & P-value \\
\hline Ayinabugna & 11.4 & 0.45 & 0.03 & 0.0002 & 25.7 & 0.50 & 0.10 & $<0.001$ & 21.5 & 0.75 & 0.34 & $<0.001$ \\
\hline Lalibela & 13.2 & 0.52 & 0.04 & $<0.001$ & 24.4 & 0.52 & 0.05 & $<0.001$ & 18.8 & 0.59 & 0.05 & $<0.001$ \\
\hline Muja & 11.7 & 0.32 & 0.03 & 0.012 & 24.6 & 0.44 & 0.10 & 0.001 & 18.2 & 0.47 & 0.04 & 0.0001 \\
\hline Kumesk & 11.1 & 0.00 & 0.00 & 1 & 23.7 & 0.50 & 0.04 & $<0.001$ & 17.4 & 0.29 & 0.02 & 0.0241 \\
\hline Kobo & 14.9 & 0.33 & 0.04 & 0.01 & 29.4 & 0.36 & 0.06 & 0.004 & 22.2 & 0.38 & 0.05 & 0.0026 \\
\hline Debrezebit & 8.9 & -0.05 & -0.01 & 0.711 & 21.7 & 0.34 & 0.02 & 0.007 & 15.3 & 0.14 & 0.01 & 0.295 \\
\hline Kone & 7.6 & -0.02 & 0.00 & 0.893 & 20.3 & 0.41 & 0.03 & 0.001 & 13.9 & 0.16 & 0.01 & 0.211 \\
\hline Gashena & 12.5 & 0.57 & 0.40 & $<0.001$ & 20.5 & -0.19 & -0.02 & 0.136 & 16.5 & 0.63 & 0.21 & $<0.001$ \\
\hline Shoga & 8.1 & 0.33 & 0.10 & 0.009 & 19.9 & 0.50 & 0.03 & $<0.001$ & 14.1 & 0.40 & 0.05 & 0.002 \\
\hline Hara & 14.9 & 0.07 & 0.00 & 0.589 & 29.1 & 0.63 & 0.10 & $<0.001$ & 22 & 0.47 & 0.03 & 0.001 \\
\hline Woldia & 12.9 & -0.25 & -0.02 & 0.052 & 26.3 & 0.35 & 0.02 & 0.005 & 19.6 & 0.02 & 0.00 & 0.893 \\
\hline
\end{tabular}




\begin{tabular}{|c|c|c|c|c|c|c|c|c|c|c|c|c|}
\hline \multirow{2}{*}{ Stations } & \multicolumn{4}{|c|}{ Minimum temperature } & \multicolumn{4}{|c|}{ Maximum temperature } & \multicolumn{4}{|c|}{ Average temperature } \\
\hline & Mean & ZMK & $\mathbf{Q}$ & P-value & Mean & ZMK & $\mathbf{Q}$ & P-value & Mean & ZMK & $\mathbf{Q}$ & P-value \\
\hline Mersa & 6.7 & 0.04 & 0.01 & 0.788 & 26.2 & 0.14 & 0.03 & 0.295 & 16.5 & 0.12 & 0.02 & 0.345 \\
\hline Sirinka & 13.5 & 0.03 & 0.00 & 0.839 & 26.7 & 0.32 & 0.02 & 0.012 & 20.1 & 0.27 & 0.01 & 0.032 \\
\hline Tekulishi & 12.8 & 0.25 & 0.03 & 0.005 & 27.8 & 0.43 & 0.10 & 0.001 & 20.3 & 0.35 & 0.04 & 0.005 \\
\hline Delib & 9.9 & -0.34 & -0.20 & 0.007 & 23.6 & -0.17 & -0.20 & 0.198 & 18.4 & 0.11 & 0.06 & 0.399 \\
\hline Zobil & 13.1 & -0.19 & -0.04 & 0.136 & 27.4 & -0.42 & -0.22 & 0.001 & 20.7 & -0.20 & -0.09 & 0.118 \\
\hline Debeko & 10.9 & 0.56 & 0.10 & $<0.001$ & 23.5 & 0.63 & 0.10 & $<0.001$ & 17.2 & 0.66 & 0.08 & $<0.001$ \\
\hline mean & 11.4 & 0.24 & 0.02 & 0.061 & 24.7 & 0.30 & 0.02 & 0.018 & 18.4 & 0.58 & 0.06 & $<0.001$ \\
\hline
\end{tabular}
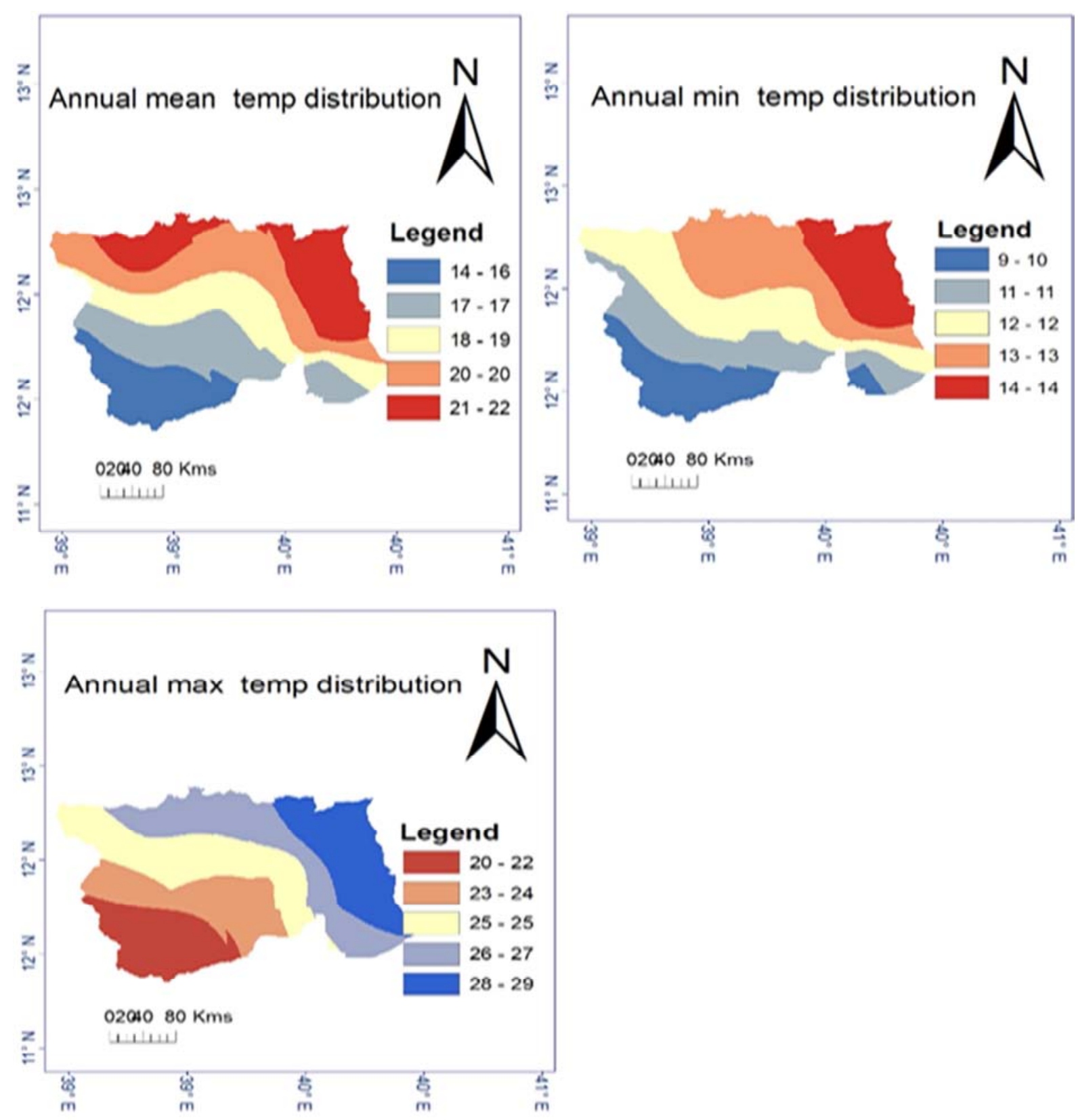

Figure 5. The spatial distribution of annual maximum, minimum and mean temperature over north wollo zone.

\subsection{Seasonal Temperature Trends}

The summary statistics for seasonal temperature trends are summarized in Table 7. The results showed that warming is varied both spatially and temporally, thus, belg and bega have warmed at higher rates than kiremt (June to September) season. In most stations, temperature is increased significantly, however, some stations, like Zobil, Delib and Gashena, showed insignificant downward change in temperature. In this regard, maximum change in warming were observed at Debeko in respective of $0.8^{\circ} \mathrm{C}, 0.7^{\circ} \mathrm{C}$ and $0.6^{\circ} \mathrm{C} /$ decade during bega, belg and kiremt season. This agrees with the result of the study by Nigusie; A. [20] over Tigray region, Ethiopia. 
Table 7. Trends of mean seasonal (kiremt, belg and bega) temperature at 17 stations (1987-2017).

\begin{tabular}{|c|c|c|c|c|c|c|c|c|c|}
\hline \multirow{2}{*}{ Stations } & \multicolumn{3}{|c|}{ Kiremt mean temperature } & \multicolumn{3}{|c|}{ Belg mean temperature } & \multicolumn{3}{|c|}{ Bega mean temperature } \\
\hline & ZMK & $\mathbf{Q}$ & P-value & ZMK & $\mathbf{Q}$ & P-value & ZMK & $\mathbf{Q}$ & P-value \\
\hline Ayinabugna & 0.40 & 0.05 & 0.001 & 0.41 & 0.05 & 0.001 & 0.65 & 0.06 & $<0.0001$ \\
\hline Lalibela & 0.48 & 0.03 & $<0.0001$ & 0.42 & 0.05 & 0.001 & 0.43 & 0.05 & 0.0005 \\
\hline Muja & 0.44 & 0.04 & 0.0004 & 0.38 & 0.04 & 0.002 & 0.43 & 0.03 & 0.0005 \\
\hline Kumesk & 0.46 & 0.03 & 0.0002 & 0.33 & 0.03 & 0.01 & 0.50 & 0.03 & $<0.0001$ \\
\hline Kobo & 0.29 & 0.04 & 0.024 & 0.31 & 0.04 & 0.014 & 0.40 & 0.05 & 0.001 \\
\hline Debrezebit & 0.46 & 0.04 & 0.0002 & 0.32 & 0.03 & 0.012 & 0.34 & 0.02 & 0.007 \\
\hline Gashena & 0.16 & 0.01 & 0.223 & 0.01 & 0.00 & 0.973 & -0.01 & -0.01 & 0.946 \\
\hline Shoga & 0.43 & 0.03 & 0.0005 & 0.27 & 0.03 & 0.032 & 0.44 & 0.02 & 0.0004 \\
\hline Hara & 0.34 & 0.02 & 0.005 & 0.39 & 0.04 & 0.002 & 0.39 & 0.04 & 0.002 \\
\hline Woldia & 0.26 & 0.02 & 0.037 & 0.25 & 0.02 & 0.052 & 0.15 & 0.01 & 0.251 \\
\hline Mersa & 0.29 & 0.03 & 0.022 & 0.17 & 0.02 & 0.199 & 0.14 & 0.02 & 0.279 \\
\hline Sirinka & 0.23 & 0.01 & 0.066 & 0.25 & 0.02 & 0.048 & 0.09 & 0.01 & 0.5 \\
\hline Tekulishi & 0.35 & 0.04 & 0.005 & 0.38 & 0.06 & 0.002 & 0.44 & 0.05 & 0.0004 \\
\hline Zobil & -0.15 & -0.03 & 0.237 & 0.05 & 0.01 & 0.686 & 0.31 & 0.04 & 0.014 \\
\hline Debeko & 0.54 & 0.06 & $<0.0001$ & 0.50 & 0.07 & $<0.0001$ & 0.64 & 0.08 & $<0.0001$ \\
\hline Areal mean & 0.33 & 0.02 & 0.009 & 0.30 & 0.03 & 0.018 & 0.41 & 0.03 & 0.001 \\
\hline
\end{tabular}

\section{Conclusion}

This paper is tried to analyze historical climate characteristics that aimed to understand the climate potential of the region intended to manage farming practices according to the potential. The study also considered around 17 meteorological stations, each which have 31 years long observed rainfall and temperature data. Trend and variability of annual and seasonal rainfall and temperature characteristics, over the last 31 years, were evaluated using rainfall anomaly index (RAI), coefficient of variation (CV) statistics and Mann-Kendal trend test approach methods. The results concluded that rainfall and temperature were varied in time and space pattern. With this, the region experienced mean annual rainfall that ranges from $531 \mathrm{~mm}$; over some pocket areas of western, central and north eastern parts to $1005 \mathrm{~mm}$ which located in south eastern of north Wollo. In terms of rainfall distribution, the area receives rainfall two times a year; from June to September (kiremt) and from February to May (Belg) period. June to September (Kiremt) is the main rainy season which most agricultural/farming/ operations undertaken, whereas, belg (February to May) is the short rainy period that some preliminary farming practices, like land preparation, for the main growing season begins. In addition, early maturing crop varieties are cultivated during the short rainy period but the practice is not always succeeded. Rainfall during belg period is erratic and unstable in terms of amount and distribution relative to the main growing season. Annual and JJAS rainfall pattern showed increasing trends, while, rainfall during Belg (February to May) period was declined over the last 31 years.

Season onset, cessation and length of growing season including rainy days are most important climate characteristics, thus, largely influencing seasonal farming practices; which practiced during preseason, like selection of crops/crop varieties, land preparation, In season, like weeding and fertilizer application, and during post season, like harvesting; of a given region. In Ethiopia, seasonal rainfall characteristics particularly onset, cessation and growing season length are major causes of year to year yield/production variation, due to the high dependency of agriculture on rain-fed system. And, as a result, the need of investigating seasonal rainfall characteristics in both spatial and temporal patterns are growing in time due to increasing risks of seasonal rainfall variations across the country. Thus, location based seasonal characteristics of onset, cessation and growing season length were investigated and the results concluded that year to year and location wide variability of seasonal rainfall characteristics were observed across the study region. According to the result, 4-July (DOY=166) and 4-Octoner $(\mathrm{DOY}=278)$, in respective order, were estimated as the mean dates that the season starts and ends. The location wide analysis also revealed that season onset ranges from 15June (at Lalibela) to 16-July (at Tekulishi); and the season terminate from 21-Sept (Zobil) to 15-October (Sirinka). In general, the season onset predominantly found to be in the month of June/July, and retreats in September/October. Variation in length of growing season and rainy days also varied from across the region. The $\mathrm{CV}$ statistic results indicated that, most of the stations were exhibited less interannual onset variation from 1987 to 2017 study period.

Temperature is a primary climatic factor that affects plant development and growth [14]. Therefore, understanding temperature characteristics of a region is significantly important for effective strategic plan that would minimize production risks of temperature. Therefore, temperature analysis was undertaken for selective stations of north Wollo zone.

\section{References}

[1] Abbas F (2013). Analysis of a historical (1981-2010) temperature record of the Punjab Province of Pakistan. Earth Interact 17: 1-15. 
[2] Agnew, C. T. and A. Chappel. 1999: Drought in the Sahel. GeoJournal 48: 299-311.

[3] Akinseye, F. (2013). Assessing the impacts of climate variability on crop yield over Sudano- Sahelian zone in Nigeria. Access Int. J. Agric. Sci., 1 (7), 91-98.

[4] Alebachew and woldeamla. (2011). A Climate Change Country Assessment Report for Ethiopia submitted to forum for environment (on behalf of ECSNCC). Epsilon International, Addis Ababa pp 5-7 and 10.

[5] Alemu, M. M., \& Bawoke, G. T. (2019). Analysis of spatial variability and temporal trends of rainfall in Amhara region, Ethiopia. Journal of Water and Climate Change, 1-16. https://doi.org/10.2166/wcc.2019.084.

[6] Asfaw A, Simane B, Hassen A, Bantider A (2018) Variability and time series trend analysis of rainfall and temperature in North central Ethiopia: a case study in Woleka Sub-basin. Weather ClimExtrem 19: 29-41.

[7] Ayalew, D; Tesfaye, K; Mamo, G; Yitaferu, B. and Bayu, W. (2012). Variability of rainfall and its current trend in Amhara region, Ethiopia. Journal of African Agricultural Research. 7 (10), 1475-1486.

[8] Bewket and Conway (2007). A note on the temporal and spatial variability of rainfall in the drought-prone Amhara region of Ethiopia. International Journal of Climatology 27, $1467-1477$.

[9] Bewket, W. (2009). Rainfall variability and crop production in Ethiopia Case study in the Amhararegion. Trondheim, s.n., and pp. 823-836.

[10] CSA, 2008. Agricultural sample survey report on area and production of crops (private peasant holdings, meher season). Statistical bulletin 417. Federal Democratic Republic of Ethiopia, Central Statistical Agency (CSA), Addis Abeba.

[11] FAO. (2010). Food Security. Policy Brief, June, 2002, Issue 2, Food and Agriculture Organization, Agricultural and Development Economics Division: http://www.fao.org/es/esa/.

[12] FAO/ Food and Agricultural Organization. 2015. Smallholder productivity under climatic variability: adoption and impact of widely promoted agricultural practices in Tanzania. EPIC, Policy Brief no. 2. Rome: FAO.

[13] Hadgu, G., Tesfaye, K., Mamo, G., and Kassa, B., 2013. Trend and variability of rainfall inTigray, Northern, Ethiopia. Analysis of meteorological data and farmers'perception. Academically Journal Environmental Science, 1 (8): 159-171.

[14] Hatfield, J. L., \& Prueger, J. H. (2015). Temperature extremes: Effect on plant growth and development. Weather and Climate Extremes, 10, 4-10. https://doi.org/10.1016/j.wace.2015.08.001.

[15] IFAD. (2016). Managing risks to improve farmers' livelihoods (Issue December).

[16] Mesikeand Esekhade, (2014). Rainfall variability and rubber production in Nigeria. African Journal of Environmental Science and Technology, 8 (1): 54-57.

[17] MoA (Ministry of Agriculture), 2011. Crop variety register. Issue No 14. Animal and Plant health regulatory directorate. Addis Ababa, Ethiopia. 234.

[18] Mugalavai, E. M., Kipkorir, E. C., Raes, D., \& Rao, M. S.
(2008). Analysis of rainfall onset, cessation and length of growing season for western Kenya. Agricultural and Forest Meteorology, $\quad 148 \quad$ (6-7), 1123-1135. https://doi.org/10.1016/j.agrformet.2008.02.013.

[19] Nicholson S. (1985). Sub-Saharan rainfall 1981-84. Jclimate Appl Meteorolo 24: 1388-1391.

[20] Niguse, A. (2015). Precipitation and temperature trend analysis in Mekele city, Northern Ethiopia, the case of Ilala meteorological station. Joural of Environment and Earth Science, 5 (19), 46-52.

[21] Organization, F. and A., \& FAO. (2015). Adaptation to climate risk and food security Evidence from smallholder farmers in Ethiopia (Issue February).

[22] Partal, T. and Kahya, E. 2006. Trend analysis in Turkish precipitation data. Hydrological. Processes, 20: 2011-2026.

[23] Pohlert, T. (2020). Non-Parametric Trend Tests and ChangePoint Detection. 1-18.

[24] Reek, T., Doty, S. R., \& Owen, T. W. (1992). A Deterministic Approach to the Validation of Historical Daily Temperature and Precipitation Data From the Cooperative Network. Bulletin of the American Meteorological Society, 73 (May 1992), 753-762. https://doi.org/10.1175/1520-0477(1992)073<0753.

[25] Seleshi Y., Camberlin, P. (2006). Recent changes in dry spell and extreme rainfall events in Ethiopia. Theoretical and Applied Climatology 83, 181-191.

[26] Sen, P. (1968). Estimates of regression coefficients based on Kendall's tau Journal of the American Statistical Association 63, 1379-1389.

[27] Sonnadara, D. U. J. (2015). The onset, retreat and the length of growing season in the north-eastern region of Sri Lanka. 3639 (December 2014), 3633-3639. https://doi.org/10.1002/joc.4237.

[28] Tung YK (1983). Point Rainfall Estimation for a Mountainous Region. J. Hydraulic Engine., 109: 1386-1393.

[29] Wagesho, N., Goel, N. K., \& Jain, M. K. (2013). Variabilité temporelle et spatiale des précipitations annuelles et saisonnières sur l'Ethiopie. Hydrological Sciences Journal, 58 (2), 354-373. https://doi.org/10.1080/02626667.2012.754543.

[30] Watson DF, Philip GM (1985), A Refinement of Inverse Distance Weighted Interpolation, Geo-Processing, 2: 315-327.

[31] WFP. (2014). Climate risks and food security in Ethiopia: analysis of climate impacts on food security and livelihoods. WFP, Rome.

[32] World Bank, 2006. Managing water resources to maximize sustainable growth: A country water resources assistance strategy for Ethiopia. World Bank, Washington, DC.

[33] World Bank (2009). Public attitudes towards climate change: findings from a multi country poll. World Development report.

[34] Wubie, A. A. (2015). Review on the Impact of climate change on crop production. Journal of Biology, Agriculture and Healthcare, 5 (13). https://doi.org/10.1007/978-3-319-144092_64.

[35] Yenigun, K. (2008). Trends in stream flow of the Euphrates basin, Turkey. Proclamation Institute of Civil Engineering Water Management. 161, 189-198. 